\title{
Penggunaan Media Sosial Dan Pemahaman Tentang Radikalisme Di Kalangan Pelajar Muslim
}

\author{
Amirah Diniaty, Susilawati, Z Zarkasih, Rian Vebrianto \\ ${ }^{1}$ Universitas Islam Negeri Sultan Syarif Kasim Riau \\ email: , Amirah.diniaty@uin-suska.ac.id
}

\section{Artikel INFO}

Diterima:03 Oktober 2020

Direvisi : 12 Januari 2021

Disetujui: 10 Maret 2021

DOI:

http://dx.doi.org/10.24014/ jp.v14i2.10897

\begin{abstract}
Abstrak
Media sosial dapat menjadi salah satu sarana penyebarluasan paham radikal terutama bagi generasi muda. Penelitian ini bertujuan untuk mengungkap penggunaan media sosial oleh pelajar musllim di tingkat sekolah menangah atas, dan kaitannya dengan pemahaman mereka tentang radikalisme. Jenis penelitian ini adalah survey terhadap 316 orang pelajar dari 5 sekolah menengah atas yang ada di Kecamatan Tampan Pekanbaru. Sampel penelitian ini diambil secara random dengan teknik purposive sampling. Data dikumpulkan dengan menggunakan angket dalam bentuk google form yang berisi pertanyaan tentang; jenis dan konten media sosial yang diakses, intensitas dan upaya yang dilakukan pelajar untuk menggunakan media sosial. Pemahaman tentang radikalisme dilihat dari jawaban responden terhadap item-item yang diklasifikasi menjadi skala likert. Hasil penelitian menunjukkan bahwa pelajar yang intensitas akses media sosialnya rendah, cendrung kurang memahami tentang radikalisme dan bahayanya. Jika dilihat dari mean jawaban responden yang intensitas penggunaan media sosialnya rendah, ternyata tidak paham tentang radikalisme. Artinya semakin mereka sering mengakses media sosial, semakin sering mereka mendapatkan informasi tentang radikalisme. Perlu ada penelitian yang lebih detil apa saja informasi tentang radikalisme yang mereka dapatkan di media sosial tersebut.
\end{abstract}

Kata kunci: media sosial, pemahaman tentang radikalisme, pelajar.

\section{Use Of Social Media And Understanding of Radicalism In Muslim Students}

\begin{abstract}
Social media can be a means of disseminating radicalism, especially for the younger generation. This study aims to reveal the use of social media by Muslim students at the school level to win over, and its relation to their understanding of radicalism. This type of research is a survey of 316 students from 5 high schools in Tampan sub-district, Pekanbaru. The research sample was taken randomly with a purposive sampling technique. Data was collected using a questionnaire in the form of google form which contains questions about; the types and content of social media accessed, the intensity and effort students make to use social media. The understanding of radicalism is seen from the respondents' answers to the items classified into a Likert scale. The results showed that students with low intensity of social media access tended to lack understanding of radicalism and its dangers. When viewed from the mean answers of respondents whose intensity of use of social media is low, it turns out that they do not understand radicalism. This means that the more often they access social media, the more often they get information about radicalism. There needs to be a more detailed study of what information about radicalism they get on social media.
\end{abstract}

Keywords: social media, understanding of radicalism, students.

\section{Pendahuluan}

Pelajar tingkat sekolah menengah adalah aset bangsa yang menurut sumber BPS, tahun 2011 ada 44 juta anak umur 10-19 tahun. Merekalah yang akan menjadi bagian dari usia produktif penduduk Indonesia di tahun 2045 yang diperkirakan berjumlah $70 \%$ dari total jumlah penduduk, yang disebut sebagai generasi emas. Generasi 
emas ini memiliki karakteristik percaya diri, kreatif, emosional, open minded, fleksibel dan selalu terhubung dengan media sosial dan internet, dan ini seringkali mendatang masalah baru dalam kehidupan mereka (Octavia (2017). Hasil survei Alvara Strategic Research tahun 2014 menjelaskan generasi usia 15-34 tahun sangat tinggi tingkat ketergantungannya pada koneksi internet. Hasil penelitian lain menunjukkan mengakses media sosial menjadi tujuan mayoritas remaja menggunakan internet mencapai 64,4\% (Pasquala, Sciacca dan Hichy, 2015), terutama dengan menggunakan handphone.

Media sosial merupakan sarana berkomunikasi dilingkungan kerja, antar anggota keluarga, dan masyarakat luas (Miller, 2016). Andreas Kaplan dan Michael Haenlein (2010) mendefinisikan media sosial sebagai sebuah kelompok aplikasi berbasis internet yang membangun di atas dasar ideologi dan teknologi Web 2.0, dan yang memungkinkan penciptaan dan pertukaran user-generated content. Azhar Asyad (Khairuni, 2016) menjelaskan beberapa ciri (karakteristik) media yang dihasilkan sosial media atau teknologi berbasis komputer untuk media pembelajaran diantaranya sebagai berikut: (a). Mereka dapat digunakan secara acak; (b). Mereka dapat digunakan berdasarkan keinginan pelajar/i atau keinginan perancang atau pengembang sebagaimana direncanakannya; (c). Biasanya gagasan yang disajikan sesuai dengan simbol dan gafik; (d). Dapat melibatkan interaktivitas pelajar/l yang tinggi. Media sosial yang digunakan pelajar memfasilitasi komunikasi, interaksi, saling kirim pesan, dan saling berbagi (sharing), dan membangun jaringan/networking (Sunarto, 2017).

Penelitian yang dilakukan oleh Vebrianto et al (2020) menunjukkan bahwa media sosial memengaruhi pemahaman beragama mahasiswa; sebanyak 100 orang $(40,0 \%)$ lebih terpengaruh oleh twitter dan 99 orang $(39,6 \%)$ oleh sosial media whatsapp kemudian diikuti oleh media lainnya youtube dan face book. Dengan interaksi yang sangat sering dan sering seramai $55,2 \%$ atau 139 orang yang menggunakan sedangkan yang jarang adalah seramai 89 orang $(35,6 \%)$ sedangkan lainnya di bawah 10 persen.

Idealnya menurut hasil penelitian Sativa (2017) akses media sosial oleh pelajar di internet sepanjang 257 menit atau sekitar 4 jam 17 menit dalam sehari. Jika lebih dari waktu itu, maka akan tergolong dalam kategori kecanduan dikenal dengan istilah compulsive mobile phone use (CMPU) (Bianchi \& Philips, 2005). Akibat yang dapat terjadi remaja tidak mampu mengatur penggunaan handphone berinternet tersebut yang berakibat ketergantungan dan permasalahan perilaku sosial (Billiex, 2012), sehingga lebih jauh kehidupan sehari-harinya tidak efektif (Lopez Fernandez, dkk., 2013). Ciri-cirinya adalah remaja pemilik mobile phone merasakan cemas ketika ponsel tidak hidup (batray mati), atau berada diluar jangkauan jaringan (Campbell, 2005). Lebih spesifik karakteristik perilaku CMPU adalah intolerance, escape from probles, withdrawal, craving, negatif consequences and low sosial motivation (Bianchi \& Philips, 2005).

Faktanya dampak negatif media sosial juga menjadi media penyebarluasan tindakan intoleransi, paham radikalisme, terorisme di Indonesia. Radikalisme atau kekerasan dalam agama dan atas nama agama saat ini cukup mengkhawatirkan (Riyadi, 2016). Hasil penelitian John Obert Voll tentang jaringan teroris bukan lagi mata rantai terpenting dalam kaitan dengan mentransformasikan politik komunitas muslim di seluruh dunia, melainkan jaringan intelektual dan pertukaran ideologi melalui media internet (Agus, 2016). Informasi berbasis jaringan internet dan hadirnya revolusi teknologi semakin membantu kelompok teroris dalam peningkatan jaringan dan propaganda paham yang mereka usung (Agus 2016). Dengan demikian, keberadaan internet telah menjadi bagian penting dalam membentuk pemikiran, perbuatan, perilaku, sekaligus kebutuhan dasar hidup manusia kini. Saking pentingnya dunia maya ini, pemikiran dan tindakan radikalisme, aksi terorisme dan bom bunuh diri kerap menggunakan teknologi mutakhir 
lengkap dengan berbagai jejaring sosialnya (Ghifari 2017).

Hasil penelitian Ghifari (2017) menemukan bahwa Kemenkominfo \& PBNU memblokir situs 300 dari 900 yang mengandung konten radikalisme di tahun 2011. Pada tahun 2015, Kemenkominfo memblokiran 22 situs (Islam) yang menyebarkan paham radikalisme. Pemblokiran ini atas permintaan BNPT dengan 3 kriteria: (1) menggunakan kekerasan dengan mengatasnamakan agama, (2) takfiri (mengkafirkan orang lain), (3) memaknai jihad secara terbatas. Data BNPT melansir sejak 2010-2015 ada 814.594 situs serupa yang sudah diblokir (Ghifari, 2017).

Berkaitan dengan penggunaan media sosial dan adanya radikalisme yang disebarluaskan melalui media ini, maka perlu dilihat bagaimana fenomena ini pada pelajar muslim di kota Pekanbaru. Pekanbaru yang mayoritas penduduknya muslim memiliki karakteristik budaya melayu yang sangat terbuka dengan perubahan (Husni Tamrin, 2007). Secara harfiah "al-Islam" bermakna ketundukan (al-iqiyad) dan kepatuhan (Ibn Zakariya. 1999;90).

Secara istilah "al-Islam" bermakna keteduhan dan kepatuhan terhadap apa yang disampaikan oleh Rasulullah Saw (alJurjani;1988;23). Maka menjadi seorang muslim bermakna menjadi orang yang tunduk dan patuh kepada aturan Allah sebagaimana yang tertuang dalam ajaran-ajaran normatif yang disampaikan oleh Nabi Muhammad Saw kepada umatnya, yang tertaun dalam al-Quran dan Sunnah. Menjadi Muslim bermakna, bahwa dirinya meyakini kebenaran ajaran Islam yang disampaikan Muhammad dan mematuhinya. Artinya, tidaklah muslim sejati jika hanya meyakini kebenaran ajaran Islam itu sendiri tampa mengamalkannya. Bahkan, tidaklah dapat disebut Muslim orang yang mengamalkan sebagian ajaran Islam tetapi tidak meyakini kebenarannya. Sebagai pelajar muslim yang mendapatkan ajaran Islam seharusnya terbentengi dengan nilainilai Islam yang orientasi hidupnya adalah akhirat (Tamimi L. and Tamimi A. 2014), terkait dengan pemahaman radikalisme yang salah.

Radikalisme merupakan suatu perbuatan penyimpangan yang dilakukan dengan anggapan bahwa semua tindakan yang dilakukan adalah benar sehingga menyalahkan segala tindakan yang dilakukan kelompok lain hingga menimbulkan perbuatan anarkis. Nur (2019) menjelaskan bahwa radikalisme muncul diakibatkan suatu kelompok dengan kondisi ekonomi relatif baik sehingga mereka terasa dipinggirkan. Selain itu kebencian mereka terhadap prilaku rezim yang berkuasa menghambat kegiatan sosial mereka. Radikalisme muncul bukan hanya dikarenakan faktor perekonomian, namun dikarenakan perbedaan ideologi dalam doktrin agama.

Sikap radikalisme muncul dengan mengatasnamakan Islam. Terorisme muncul diakibatkan sikap radikal yang memuncak sudah menjiwai seorang individu sehingga merusak bahkan membunuh sekelompok yang dianggap ancaman serta jihad baginya. Anastasia (2018) menjelaskan terorisme dan radikalisme dapat mengguncang rasa kelndonesiaan yang beragam, tidak toleran dan tidak menerima terhadap perubahan. Selain itu Hasnah dan Rasyidin (2019) sikap terorisme memasuki era millennium ketiga, serangkaian peristiwa pemboman situs milik negara Barat telah terjadi, dan menimbulkan citra negatif dunia Barat terhadap Indonesia.

Terdapat empat ciri utama radikalisme yaitu: (a) gerakan atau paham anti NKRI (b) gerakan atau paham yang anti pancasila (c) gerakan atau paham yang menyebarkan intoleransi (d) gerakan atau paham yang mengajak ke tindakan kekerasan (Kartini, 2019).

Ciri-ciri sikap radikalis sangat membahayakan apabila tidak dideteksi sedini mungkin, sehingga dapat memengaruhi suatu individu atau kelompok untuk membentuk komunitas radikalisme. Arjuli (2018) menjelaskan ada beberapa cirri yang bisa dikenali dari sikap atau paham radikal yaitu intoleransi, fanatic, ekslusif dan revolusioner. 
Tulisan ini bertujuan mendeskripsikan penggunaan media sosial oleh pelajar muslim dan pemahaman mereka tentang radikalisme. Hasil penelitian ini menjadi sinyal yang harus diwaspadai orang tua, para pendidik tentang seberapa mengkhawatirkannya generasi milenial muslim dalam menggunakan internet.

\section{Metode}

Penelitian ini menggunakan pendekatan kuantitatif dengan metode survei lapangan. Survei dilakukan dengan menggunakan google form pada responden yaitu pelajar muslim di sekolah menengah atas berbasis Islam di kota Pekanbaru, dan sekolah menengah umum.

\section{Subjek}

Subjek penelitian ini adalah pelajar muslim berjumlah 316 orang dari 5 sekolah menengah atas berbasis Islam yang ada di kecamatan Tampan Pekanbaru. Sampel penelitian ini diambil secara random dengan teknik purposive sampling.

Gambaran 316 orang responden penelitian berdasarkan jenis kelamin dapat dilihat dalam Tabel 1:

Tabel 1. Jenis Kelamin Responden

\begin{tabular}{|c|c|c|c|c|c|}
\hline & & Frequency & Percent & Valid Percent & $\begin{array}{l}\text { Cumulative } \\
\text { Percent }\end{array}$ \\
\hline Valid & Laki-laki & 107 & 33.9 & 33.9 & 33.9 \\
\hline & Perempuan & 209 & 66.1 & 66.1 & 100.0 \\
\hline & Total & 316 & 100.0 & 100.0 & \\
\hline
\end{tabular}

Dari Tabel 1 di atas diketahui yang menjadi responden dalam penelitian ini yaitu sebanyak 316 orang yang terdiri atas 107 laki-laki dan 209 perempuan, kemudian untuk Variasi jurusan kelas responden, dapat dilihat dalam tabel 2

Tabel 2. Jurusan Responden di SMA

\begin{tabular}{|c|c|c|c|c|c|}
\hline \multicolumn{3}{|r|}{ Frequency } & Percent & Valid Percent & $\begin{array}{c}\text { Cumulative } \\
\text { Percent }\end{array}$ \\
\hline Valid & TPA & 206 & 65.2 & 65.2 & 65.2 \\
\hline & TPS & 110 & 34.8 & 34.8 & 100.0 \\
\hline & Total & 316 & 100.0 & 100.0 & \\
\hline
\end{tabular}

Sedangkan pada Tebl 2 di perlihatkan bahwa variasi responden terdiri dari jurusan IPA (sains) sebanyak 206 dan IPS (sosial) 110. Dengan data ini diharapkan akan dapat menjawab pertanyaan penelitain secara lebih spesifik.

\section{Instrumen Penelitian}

Data dikumpulkan dengan menggunakan angket dalam bentuk google form yang berisi pertanyaan tentang; jenis dan konten media sosial yang diakses, intensitas dan upaya yang dilakukan pelajar untuk menggunakan media sosial. Untuk bagian ini berupa angket gabungan tertutup dan terbuka dengan pilihan jawaban yang disediakan, dan responden dapat menuliskan jawaban sendiri dikolom yang disediakan.

Indikator angket pemahaman tentang radikalisme dikembangkan dari tiga ciri radikalisme yang dikemukakan BNPT (Ghifari, 2017) meliputi (1) menggunakan kekerasan dengan mengatasnamakan agama, (2) takfiri (mengkafirkan orang lain), (3) memaknai jihad secara terbatas. Pemahaman responden dilihat dari jawaban responden terhadap itemitem yang diklasifikasi menjadi skala likert dengan pilihan Sangat Setuju (SS), Setuju (S), Ragu-ragu (R), Tidak Setuju (TS) atau Sangat Tidak Setuju (STS). 


\section{Analsis Data}

Data dianalisis secara deskriptif kuantitatif menggunakan software SPSS versi 22 untuk menjelaskan frekuansi dan persentase dari data yang di tampilkan.

\section{Hasil}

Penggunaan Media Sosial oleh Pelajar Muslim

1. Jenis media sosial yang paling banyak di digunakan pelajar adalah Instagram $(34,17 \%)$, Whatshap $(32,22 \%)$ dan Facebook $(31,02 \%)$, yang dapat dilihat dalam tabel 3 berikut:
Tabel 3. Jenis Media Sosial yang diakses

\begin{tabular}{llrr}
\hline & & Frequency & \multicolumn{1}{c}{ Percent } \\
Valid & Instagram & 108 & 34,17 \\
& Whatsapp & 102 & 32.22 \\
& Faceboook & 98 & 31.02 \\
& Snap chat & 2 & 0.63 \\
& Tidak mengisi & 5 & 1.58 \\
& Lainnya & 1 & 0.31 \\
\multicolumn{1}{l}{ Total } & & 316 & 100.0 \\
\hline
\end{tabular}

2. Intensitas penggunaan media sosial terlihat dalam tabel 4 bahwa sebagian besar (44\%) antara 3-7 jam dalam sehari. Bahkan ada yang mengakses lebih dari 10 jam dalam sehari $(4,7 \%)$ dan tampa batas $(0,9 \%)$.

Tabel 4. Intensitas penggunaan Internet

\begin{tabular}{lrrrr} 
& Frequency & Percent & Valid Percent & $\begin{array}{c}\text { Cumulative } \\
\text { Percent }\end{array}$ \\
\hline 1 - 3 Jam & 50 & 15.8 & 15.8 & 15.8 \\
$>$ 3 - < 7 Jam & 139 & 44.0 & 44.0 & 59.8 \\
\hline 7 - 10 Jam & 79 & 25.0 & 25.0 & 84.8 \\
\hline > 10 Jam & 15 & 4.7 & 4.7 & 89.6 \\
\hline Tidak Terbatas & 3 & .9 & .9 & 90.5 \\
\hline Tidak menjawab & 30 & 9.5 & 9.5 & 100.0 \\
\hline Total & 316 & 100.0 & 100.0 & \\
\hline
\end{tabular}

3. Perangkat dan pulsa untuk mengakses media sosial

Hampir semua responden $(85,8 \%)$ memiliki sendiri handphone untuk mengakses media sosial, sebagai mana dijelaskan dalam tabel 5 berikut:

Tabel 5. Kepemilikan Perangkat handphone untuk Akses media sosial

\begin{tabular}{llrrrr}
\hline & Frequency & Percent & \multicolumn{2}{c}{$\begin{array}{c}\text { Valid } \\
\text { Percent }\end{array}$} & $\begin{array}{c}\text { Cumulative } \\
\text { Percent }\end{array}$ \\
Valid & Milik Sendiri & 271 & 85.8 & 85.8 & 85.8 \\
\cline { 2 - 6 } & Milik Orang Tua & 35 & 11.1 & 11.1 & 96.8 \\
\cline { 2 - 6 } & Pinjam punya teman & 4 & 1.3 & 1.3 & 98.1 \\
\hline $\begin{array}{l}\text { Menggunakan Perangkat untuk } \\
\text { Mengakses Internet Milik Sendiri }\end{array}$ & 6 & 1.9 & 1.9 & 100.0 \\
Milik Orang Tua dan Rental & & & & \\
\hline Total & 316 & 100.0 & 100.0 & \\
\hline
\end{tabular}

Untuk dapat mengakses media sosial sebagian dari responden $(58,28 \%)$ menggunakan uang jajan mereka sendiri. Konten yang diakses responden di media sosial ternyata juga meliputi materi akademik, agama, dan paling banyak untuk chatting pribadi (31\%). Hal ini dapat dilihat dalam tabel 6 berikut: 
Tabel 6. Konten yang diakses

\begin{tabular}{|c|c|c|c|c|c|}
\hline & & Frequency & Percent & $\begin{array}{l}\text { Valid } \\
\text { Percent }\end{array}$ & $\begin{array}{l}\text { Cumulative } \\
\text { Percent }\end{array}$ \\
\hline \multirow[t]{5}{*}{ Valid } & Akademik & 89 & 28.2 & 28.2 & 28.2 \\
\hline & Agama & 47 & 14.9 & 14.9 & 43.0 \\
\hline & Hiburan & 82 & 25.9 & 25.9 & 69.0 \\
\hline & Chatting pribadi & 98 & 31.0 & 31.0 & 100.0 \\
\hline & Total & 316 & 100.0 & 100.0 & \\
\hline
\end{tabular}

4. Pemahaman tentang Radikalisme oleh Pelajar

Pemahaman pelajar tentang radikalisme dan bahayanya masih tergolong rendah terlihat dari dari jawabannya terhadap item-item yang diklasifikasi sebagaimana dilihat dalam tabel 7 berikut:

Tabel 7. Tingkat Pemahaman Responden tentang Radikalisme

\begin{tabular}{c|c|c|c}
\hline \multirow{2}{*}{ No } & \multirow{2}{*}{ Klasifikasi } & \multicolumn{2}{c}{ Jawaban Responden } \\
\cline { 3 - 4 } & Sangat Memahami & 48 & Prekuensi \\
\hline 1 & Memahami & 132 & 15,18 \\
\hline 2 & Kurang Memahami & 125 & 41,77 \\
\hline 3 & Tidak Memahami & 10 & 39,55 \\
\hline 4 & Sangat Tidak Memahami & 1 & 3,16 \\
\hline 5 & Total & 316 & 0,31 \\
\hline & & & 100 \\
\hline
\end{tabular}

5. Intensitas Penggunaan Media Sosial dan Pemahaman tentang Radikalisme di kalangan Pelajar, dapat dilihat pada tabel 8 berikut:

Tabel 8. Intensitas penggunaan media sosial dan pemahaman tentang Radikalisme dikalangan pelajar

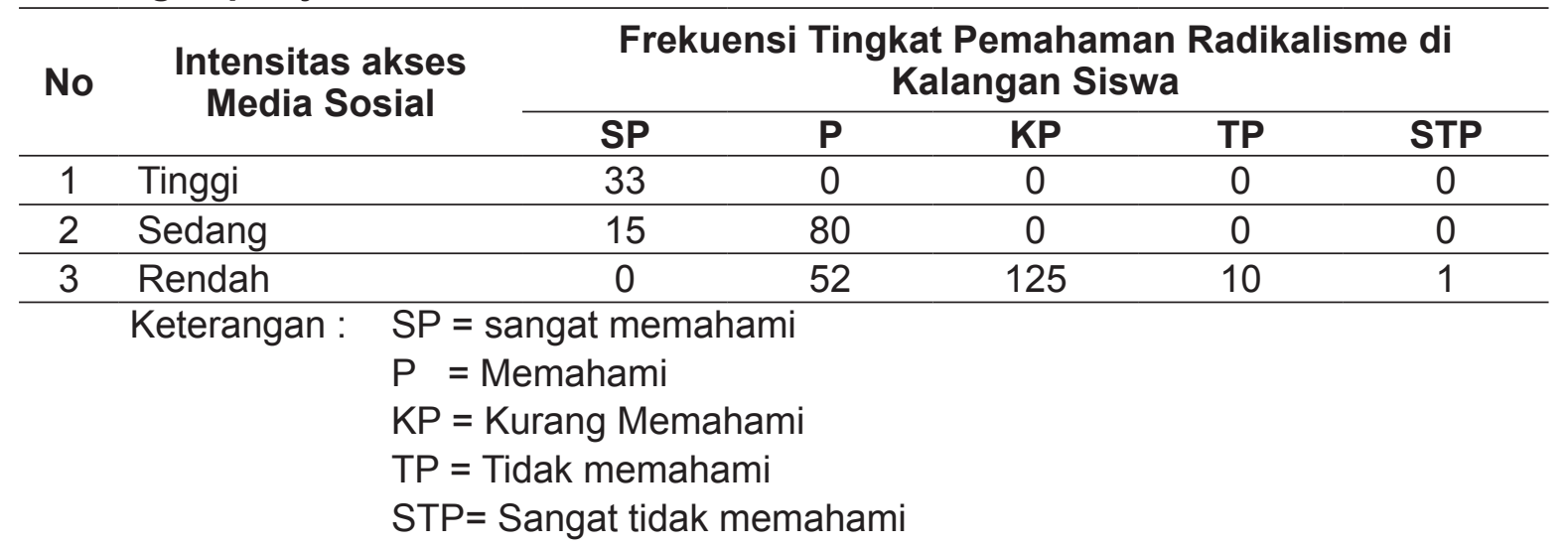

Dari tabel 8 di atas dapat dilihat bahwa jumlah pelajar yang akses media sosialnya rendah lebih banyak kurang memahami tentang radikalisme dan bahayanya.

\section{Pembahasan}

Temuan penelitian memetakan penggunaan media sosial oleh pelajar muslim lebih banyak pada jenis instagram, whatshapp dan facebook, dengan waktu yang digunakan untuk mengakses sebagian besar (44\%) antara 3-7 jam dalam sehari. Hampir semua responden $(70,9 \%)$ menggunakan handphone/smartphone untuk mengakses internet, dan $85,8 \%$ memiliki sendiri handphone tersebut. Untuk dapat mengakses 
media sosial sebagian dari responden (58, $28 \%$ menggunakan uang jajan mereka sendiri. Konten yang diakses responden banyak (31\%) pada chatting pribadi, dan akademik $(28,2 \%)$.

Hasil penelitian ini sesuai dengan studi lain yang didanai oleh UNICEF dan dilaksanakan oleh Kementerian Kominfo (2014) dengan menelusuri aktivitas online dari sampel anak dan remaja usia 10-19 (sebanyak 400 responden) yang tersebar di seluruh negeri dan mewakili wilayah perkotaan dan perdesaan, diperoleh data setidaknya 30 juta anak-anak dan remaja di Indonesia merupakan pengguna internet, dan media digital saat ini menjadi pilihan utama saluran komunikasi yang mereka gunakan. 80 persen responden yang disurvei merupakan pengguna internet, dengan bukti kesenjangan digital yang kuat antara mereka yang tinggal di wilayah perkotaan dan lebih sejahtera di Indonesia, dengan mereka yang tinggal di daerah perdesaan (dan kurang sejahtera).

Gambaran penggunaan internet pada pelajar tingkat SLTA di kecamatan Tampan Pekanbaru ternyata mengkhawatirkan karena idealnya durasi akses internet menggunakan handphone atau smartphone menurut hasil penelitian (Sativa, 2017), sepanjang 257 menit atau sekitar 4 jam 17 menit dalam sehari. Jika lebih dari waktu itu, maka anak akan tergolong dalam kategori kecanduan dikenal dengan istilah compulsive mobile phone use (CMPU) (Bianchi \& Philips, 2005).

Temuan penelitian Subu (2019) tujuan penggunaan internet bagi remaja adalah mengakses informasi global, sumber belajar, media dan jejaring sosial, hiburan, permainan, dan partisipasi dalam grup atau komunitas online. Hasil penelitian Mulyana dan Afriani (2017) menemukan bahwa 20\% remaja menggunakan smartphone untuk mengakses media sosial, 14,7\% untuk mendengarkan musik, $12,5 \%$ untuk mengirim pesan, $12,1 \%$ bermain game, $11,5 \%$ untuk menelpon, $8,1 \%$ menonton video, 3,3\% untuk email dan sisa $2,3 \%$ lainnya untuk keperluan lain.
Hasil penelitian lain menunjukkan mengakses media sosial menjadi tujuan mayoritas remaja menggunakan internet mencapai 64,4\% (Pasquala, Sciacca dan Hichy, 2015). Selain itu internet juga dijadikan sebagai media belajar yang dianggap efektif karena dapat digunakan secara acak berdasarkan keinginan anak, gagasan yang disajikan sesuai dengan simbol dan grafik, dan dapat melibatkan interaktivitas siswa yang tinggi (Khairuni, 2016). Young (2004), menjelaskan kebanyak orang menggunakan internet untuk memperbaiki mood dan melupakan tentang masalah pribadi mereka. Mereka menggunakan internet untuk menyalurkan perasaan negatif sehingga berharap lebih baik. Mereka mengemukakan tentang permasalahan pribadi mereka pada media sosial untuk katarsis yang dapat mengakibatkan timbulnya permasalahan baru.

Hal yang menarik dari penelitian ini bahwa jumlah pelajar yang akses media sosialnya rendah lebih banyak kurang memahami tentang radikalisme dan bahayanya. Jika dilihat dari mean jawaban responden yang penggunaan media sosialnya rendah, ternyata tidak paham tentang radikalisme dari skor mean mencapai 70,10 , dan mean 59,00 untuk sangat tidak paham. Ini berarti bahwa akses terhadap media sosial memberikan informasi tentang radikalisme. Namun perlu diwaspadai adanya hoax yang dapat memberikan informasi tidak benar pada pelajar melalui media sosial. Hoax adalah perbuatan dengan sengaja (penipuan dan kebohongan) yang bertujuan agar targetnya menerima dan mempercayai informasi yang salah-dalam bentuk tulisan, gambar, dan cerita lisan yang akhir-akhir ini lebih banyak dalam bentuk berita palsu. Survei Mastel (2017) menjelaskan bahwa hoax lebih banyak berisi isu sosial politik $(91,8 \%)$, tentang sara $(86,6 \%)$ dan kesehatan (41,2\%). Paham radikalisme dapat tergolong dalam isu politik dan sara dapat tersebar berupa hoax, yang harus diwaspadai oleh pelajar muslim saat mengakses media sosial.Untuk itu perlu dikembangkan literasi counter radikalisme 
berbasis media sosial (Farah Noersativa, agent of change terutama oleh pendidik 2018). Peran pemerintah diperlukan dan orang tua siswa. Prakteknya berupa mengingat pola monitoring jaringan radikal penyebaran informasi dalam bentuk gambar, sering menggunakan media sosial, sehingga meme, tulisan, video yang mencounter literasi melawan radikalisme berbasis dengan penyebaran radikalisme, yang bersinergi media sosial menjadi sangat penting.

Literasi counter radikalisme berbasis media sosial ini menarik untuk dikembangkan, dengan melibatkan semua pihak sebagai dengan pemerintah dan masyarakat secara luas. Kerjasama counter radikalisme dengan literasi berbasis media sosial sebagaimana digambarkan dalam bagan berikut :

Pendidik sebagai

Agent of change

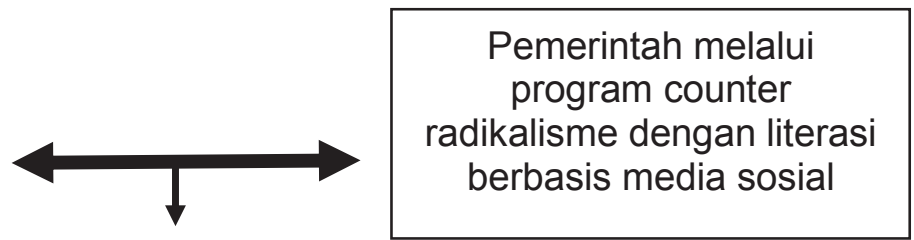

Penyebaran informasi dalam bentuk gambar, meme, tulisan, dan video yang mengcounter radikalisme, melalui Instagram whatshapp, dan fasbook

Gambar 1.Pola kerjasama dalam literasi counter radikalisme berbasis media sosial bagi remaja.

\section{Kesimpulan}

Temuan penting penelitian ini adalah bahwa semakin tinggi intensitas remaja mengakses media sosial, maka akan semakin sering mereka mendapatkan informasi tentang radikalisme. Perlu diwaspadai informasi yang tidak benar (hoaxs) dari media sosial yang diakses.

Perlu dibentuk sikap seorang pelajar muslim yang cerdas dalam mengelola informasi dan menggunakan sosial media agar terhindar dari berita hoaxs dan radikalisme. Agama Islam mengajarkan pemeluknya untuk saling menghormati, harmonis, damai dan hidup sejahtera. Munculnya garis keras yang mengatasnamakan Islam dalam interaksi antar manusia dimungkinkan oleh kesalahan dalam memahami ayat dalam Alquran seperti kewajiban jihad dengan jiwa dan harta (Q.S. 9: 41, Q.S. 2: 216, Q.S. 5: 44, Q.S. 3:104).
Dari penelitian ini disarankan adanya sosialiasi yang komprehensif dan intens tentang penggunaan media sosial sehat bagi remaja guna menangkal paham radikalisme yang bertentangan dengan ajaran Islam sebagai agama pembawa kedamaian. Selain itu kerjasama pendidik dengan masyarakat khususnya orangtua dan kepedulian pemerintah diperlukan melakukan literasi counter radikalisme. Upaya ini dilakukan dengan cara menyebarkan informasi yang benar dan tidak hoak tentang bahaya radikalisme melalui media sosial yang banyak digunakan remaja sebagaimana hasil penelitian ini yaitu instagram, whatsapp, dan facebook.

\section{Daftar pustaka}

Agus SB, (2016). Deradikalisasi Dunia Maya, Melncegah Simbiosis Terorisme dan Media. Jakarta:Daulat Press. 
Al-Jurjani, Ali bin Muhammad. (1988). Kitab alTa'rifat. Bairut; Dar al-Kutub al-'Ilmiyah

Anastasia Yuni Widyaningrum, Noveina Silviyani Dugis. (2018). Terorisme Radikalisme dan Identitas Keindonesiaaan. Jurnal Studi Komunikasi. (2) 1 32-67

Anderson, L. W., \& David R. Krathwohl, D. R., et al. .(2001). A Taxonomy for Learning, Teaching, and Assessing: A Revision of Bloom's Taxonomy of Educational Objectives. Allyn \& Bacon. Boston, MA (Pearson Education Group).

Arjulin. (2018). Peran Forum Koordinasi Pencegahan Terorisme (FKPT) Dalam Pencegahan Paham Radikalisme Dan Terorisme Di Sumatera Selatan. Skripsi yang dipublikasikan Program Studi Politik Islam Fakultas Adab Dan Humaniora Universitas Islam Negeri Raden Fatah Palembang

Bianchi \& Philips, J.G. (2005). Psychological predictor of problem mobile phone use and pschological parameters in young adults. International Joural of Public Health, 57, 437-441.

Billiex.. (2012). Problematic Use of the Mobile Phone; A Literatur Riview and a Pathways Model. Current Psychiatry Riviews, Volume 8, No.4

Creswell, J., W. (2012) Educational Research: palnning, conducting abd evakuating quantitative dan qualitative research (4th ed.). Boston; Pearson Education, Inc.,

Dick, W. \& Carey, L. (1985). The systematic design of instruction. (2nd ed.). Glenview, IL: Scott, Foresman \& Co.

Endri Kusumaratih. 4 Januari, (2017). Renik Media Sosial. Hadila, hlm, 9.

Farah Noersativa. (2018). KPAI Usul Model Pencegahan Radikalisme Berbasis Masyarakat. Republika.Jumat 18 May 2018 02:14 WIB. https://www.republika. co.id/berita/nasional/ umum/18/05/18/ p 8 vk6w370-kpai-usul-modelpencegahan-radikalisme-berbasismasyarakat

Gagne, R. M., Wager, W. W., Golas, K. C. \& Keller, J. M. (2005). Principles of
Instructional Design. Fifth edition, Singapore: Wadsworth Thomson Learning

Ghifari, Iman Fauzi. (2017). Radikalisme Di Internet. Religious: Jurnal Agama dan Lintas Budaya 1, 2 (Maret 2017): 123134

Hasnah Nasution dan Al Rasyidin. (2019). Respons Al-Ittihadiyah Di Sumatera Utara Terhadap Radikalisme. Journal Of Contemporary Islam And Muslim Societies. (3) 1

https://kominfo.go.id/index.php/content/ detail/3834/ Riset Kominfo dan UNICEF Mengenai Perilaku Anak dan Remaja Dalam Menggunakan Internet SIARAN PERS NO. 17/PIH/KOMINFO/2/2014 18-2-2014, diakses tanggal 23 Februari 2018.

Husni Thamrin. (2007). Phenomenon, Culture, Social-Religion, and Education. Pekanbaru: LPPM UIN Suska Riau

Ibn Zakariya, Abu Hasan Ahmad bin Faris. (1999). Mu`jam Maqayis al-Lughah. Bairut: Dar al-Jayl

Kaplan, Andreas M.; Michael Haenlein .(2010). Users of the World, Unite! The Challenges and Opportunities of Social Media. Business Horizons.

Kartini Dwi Sartika, Taufan Teguh Akbari, dan Zhafran Tsany Yudizon. (2019). Analisa Upaya Counter-Radicalism Di Kalangan Kampus Menggunakan Pendekatan $\mathrm{Cmm}$ (Coordinated Management Of Meaning). Ikraith-Humaniora. (3) 2

Kementerian Kesehatan RI. (2014). Situasi Kesehatan Reproduksi Remaja. Jakarta: Kementerian Kesehatan RI.

Kertopati, Susaningtyas. (2015). Publik Perlu Kekebalan Sosial Agar Tidak Mudah Terpengaruh Propaganda Terorisme. Rakyat Merdeka.

Khairuni, N. (2016). Dampak Positif Dan Negatif Sosial Media Terhadap Pendidikan Akhlak Anak (Studi Kasus di SMP Negeri 2 Kelas VIII Banda Aceh). Jurnal Edukasi Jurnal Bimbingan Konseling. 2:91-106.

Leni Winarni, (2014). Media Massa dan Isu Radikalisme Islam, dalam Jurnal 
Komunikasi Massa Vol. 7 No. 2, Juli 2014:164-165 .

Lopez Fernandez, O., Honrubia-Serrano,L., Freixa-Blanxart, M., \& Gibson, W. (2013). Prevelence of Problematic Mobile Phone Use in British Adolesence. Cyberpsychol Behav Social Netw, 17:91-98

Miller, Daniel, et al. (2017). How the World Changed Social Media. UCL Press. Source: $\quad$ https://www.jstor.org/stable/j. ctt1g69z35.8

Mulyana, S., dan Afriani. (2017). Huubngan antara self esteem dengan smartphone addiction pada remaja SMA di Kota Banda Aceh. Jurnal Pskogenesis, Volume 5, No.2

Nafi' Muthohirin. (2015). Radikalisme Islam dan Pergerakannya di Media Sosial, Jurnal Afkaruna, Faculty of Islamic Studies, Universitas Muhammadiyah Yogyakarta Vol 11, No: Juli - Desember 2015:240-259

Ngafifi, M. (2014). Kemajuan Teknologi Dan Pola Hidup Manusia Dalam Perspektif Sosial Budaya. Jurnal Pembangunan Pendidikan: Fondasi dan Aplikasi [Online] 2.

Nurdiyanah,Rika Dwi Ayu Parmitasari,Irvan Muliyadi, Serliah Nur, Nadyah Haruna. (2016). Panduan pelatihan dasar asset based community-driven development (abcd). Makasar: Nur Khairunnisa.

Nur Khoiri. (2019). Radikalisme Agama dalam Pandangan Elit Muhammadiyah dan Nahdlatul Ulama. ISBN 978-602-532805-3.

Octavia Devalucia Dwi Anggraeny. (2017). Pernikahan Generasi Millinnial. Jakarta: Gramedia.

Pasquale C.D., Sciacca,F., \& Hichy,Z.(2015). Smartphone addiction and dissociative experience: an investigation in Italian adolescents ages bewteen 14 and 19 year. International Journal of Psychology \& Behavior Analysis, 1(2), 1-4

Riyadi, Hendar. (2016). Koeksistensi damai dalam masyarakat muslim modernis", Wawasan: Jurnal IImiah Agama dan Sosial Budaya 1, no. 1:18, doi:10.15575/ jw.v39i1.575

Sativa, R. L. (2017). How long is the ideal time of using Gadget? https://inet.detik. com/cyberlife/d-3398914/berapa-lamawaktu-ideal-gunakangadget. detik.com

Subu, M. A., Rahmawati, P., Waluyo, I., \& Agustino, R. (2019). Addiction of Internet Gaming and Status Body Mass Index 9BMI) on Teenagers at Junior High School in 2018. Journal of Science and Health Technology, 6(2), 167-174.

Sulidar Fitri. (2017). Dampak Positif Dan Negatif Sosial Media Terhadap Perubahan Sosial Anak. Naturalistic: Jurnal Kajian Penelitian Pendidikan dan Pembelajaran 1, 2: 118-123.

Sunarto, Andang. (2017). Dampak Media Sosial Terhadap Paham Radikalisme. Nuansa Vol. X, No. 2

Vebrianto, R., Khalilullah, M., \& Syukri, M. (2020). Mapping Students' Understanding of Radicalism in Riau Province. Journal of Hupo_Linea, 1(1), 1-11.

Young, K. S. (2004). Internet Addiction: A New Clinical Phenomenon and Its Consequences. American Behavioural Scientist, 48(4), 402-415. https:// doi.org/10.1177/0002764204270278 